\title{
Final Technical Report on Fluoride Salt Study
}

Fuel Cycle Research \& Development

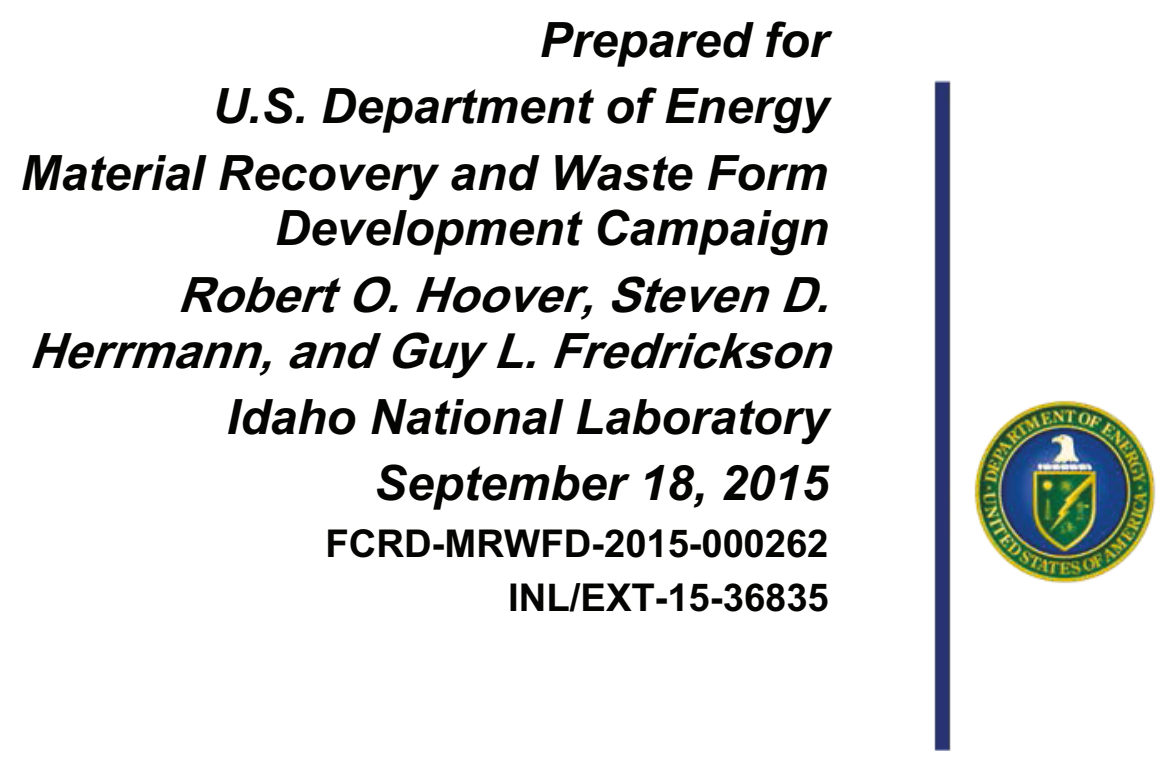




\section{DISCLAIMER}

This information was prepared as an account of work sponsored by an agency of the U.S. Government. Neither the U.S. Government nor any agency thereof, nor any of their employees, makes any warranty,

expressed or implied, or assumes any legal liability or responsibility for the accuracy, completeness, or usefulness, of any information, apparatus, product, or process disclosed, or represents that its use would not infringe privately owned rights. References herein to any specific commercial product, process, or service by trade name, trade mark, manufacturer, or otherwise, does not necessarily constitute or imply its endorsement, recommendation, or favoring by the U.S. Government or any agency thereof. The views and opinions of authors expressed herein do not necessarily state or reflect those of the U.S. Government or any agency thereof. 
Final Technical Report on Fluoride Salt Study

September 18, 2015 


\section{SUMMARY}

This report fulfills the Level 3 Milestone No. M3FT-15IN0311022 titled, "Uranium Electrorefining Using Fluoride Salt" within the Department of Energy (DOE) Work Package No. FT-15IN031102 titled, "U/TRU Codeposition and Fluoride Salt Studies - INL". This work package falls under the Fuel Cycle Research and Development (FCR\&D) Materials Recovery and Waste Form Development (MRWFD) Program 1.02.03.11 titled "Domestic Echem".

The electrorefining of uranium in a LiF-NaF-KF, or FLiNaK, salt containing $\mathrm{UF}_{3}$ has been performed. Several gram-scale electrodeposits of uranium were collected exhibiting a dendritic morphology similar to uranium electrorefining in chloride salts. Additionally, cyclic voltammetry experiments have been performed at $773 \mathrm{~K}$ in $\mathrm{FLiNaK}-\mathrm{UF}_{4}, \mathrm{FLiNaK}_{-} \mathrm{UF}_{3}$, and $\mathrm{FLiNaK}-\mathrm{UF}_{3}-\mathrm{LaF}_{3}$ salt mixtures to analyze the feasibility of electrorefining uranium in the FLiNaK salt containing lanthanides. Results are promising, showing a $0.48 \mathrm{~V}$ potential window between uranium and lanthanum depositions. 
Final Technical Report on Fluoride Salt Study

September 18, 2015 


\section{CONTENTS}

SUMMARY iv

ACRONYMS ix

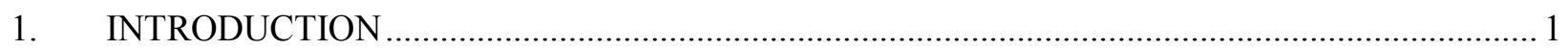

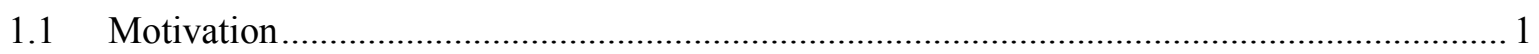

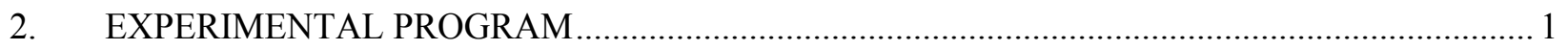

2.1 Experimental Materials and Equipment ........................................................................... 1

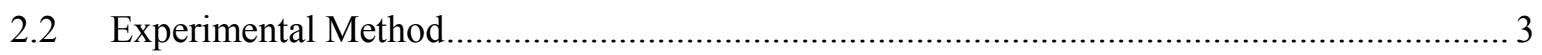

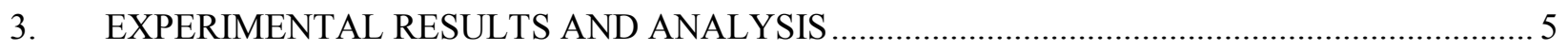

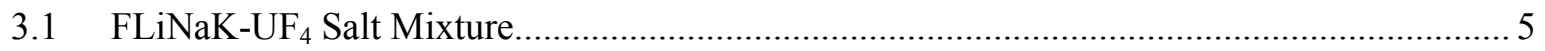

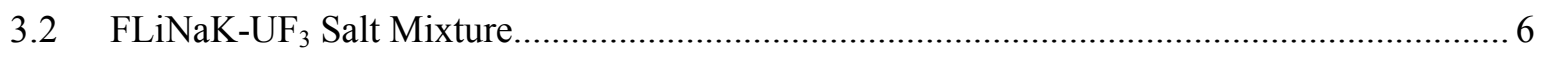

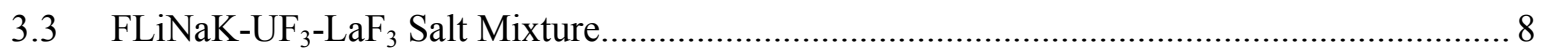

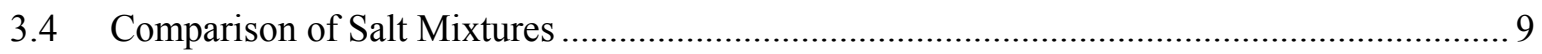

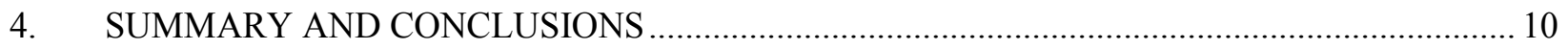

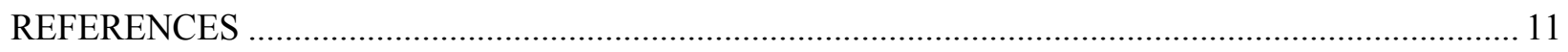

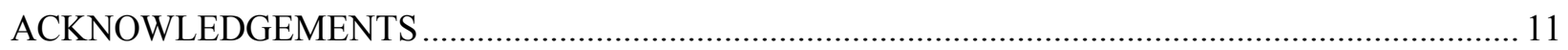

FIGURES

Figure 1. Uranium tetrafluoride $\left(\mathrm{UF}_{4}\right)$ salt used in electrochemical experiments.................................. 2

Figure 2. Depleted uranium metal used in the uranium electrorefining experiments............................... 2

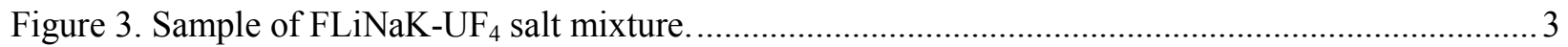

Figure 4. Experimental setup in the argon atmosphere radiological glovebox in FASB.......................... 4

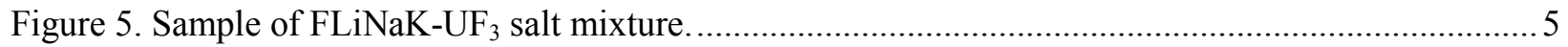

Figure 6. Cyclic voltammograms of FLiNaK-UF $4(0.8 \mathrm{~mol} \%)$ at $773 \mathrm{~K}$. Working electrode: Ni. Scan rate: $25 \mathrm{mV} / \mathrm{s}$......

Figure 7. Examples of uranium metal electrodeposited onto a Ni cathode at $0.3 \mathrm{~A}$ applied current from $\mathrm{FLiNaK}-\mathrm{UF}_{4}-\mathrm{UF}_{3}(0.8-1.1 \mathrm{~mol} \% \mathrm{U})$ at $773 \mathrm{~K}$. Equivalent charge passed: (a) 3.0 $\mathrm{g} \mathrm{U}$, (b) $0.5 \mathrm{~g} \mathrm{U}$, and (c) $6.0 \mathrm{~g} \mathrm{U}$.

Figure 8. Cyclic voltammograms of FLiNaK- $\mathrm{UF}_{3}(1.1 \mathrm{~mol} \%)$ at $773 \mathrm{~K}$. Working electrode: Ni. Scan rate: $25 \mathrm{mV} / \mathrm{s}$......

Figure 9. Cyclic voltammograms of FLiNaK- $\mathrm{UF}_{3}-\mathrm{LaF}_{3}(1.1-0.55 \mathrm{~mol} \%)$ at $773 \mathrm{~K}$. Working electrode: Ni. Scan rate: $25 \mathrm{mV} / \mathrm{s}$.

Figure 10. Comparison of cyclic voltammograms in $\mathrm{FLiNaK}_{-} \mathrm{UF}_{4}, \mathrm{FLiNaK}_{-} \mathrm{UF}_{3}$, and FLiNaK$\mathrm{UF}_{3}-\mathrm{LaF}_{3}$ at $773 \mathrm{~K}$. Working electrode: Ni. Scan rate: $25 \mathrm{mV} / \mathrm{s}$. 


\section{TABLES}

Table 1. Summary of potentials vs glassy carbon quasi-reference electrode determined from cyclic voltammetry in the three salt mixtures. 
Final Technical Report on Fluoride Salt Study 


\section{ACRONYMS}
A Amps
CV Cyclic Voltammetry
DU Depleted uranium
$\mathrm{E}_{\mathrm{d}} \quad$ Deposition potential
$\mathrm{E}_{\mathrm{pa}} \quad$ Anodic peak potential
$\mathrm{E}_{\mathrm{pc}} \quad$ Cathodic peak potential
ER Electrorefining
FASB Fuels and Applied Science Building
FLiNaK Lithium fluoride - sodium fluoride - potassium fluoride eutectic salt
g Grams
INL Idaho National Laboratory
K Kelvin
$\mathrm{LaF}_{3} \quad$ Lanthanum trifluoride
LiCl-KCl Lithium chloride - potassium chloride eutectic salt
MSF-III Molten Salt Furnace-III
$\mathrm{mV} \quad$ millivolt
$\mathrm{Ni} \quad$ Nickel
OCP Open circuit potential
Ta Tantalum
U Uranium
$\mathrm{UF}_{3} \quad$ Uranium trifluoride
$\mathrm{UF}_{4} \quad$ Uranium tetrafluoride 



\section{FINAL TECHNICAL REPORT ON FLUORIDE SALT STUDY}

\section{INTRODUCTION}

The electrorefining of uranium in chloride molten salts is a method currently used at Idaho National Laboratory (INL) to treat used metallic fuel from the Experimental Breeder Reactor-II. In this process, uranium metal (U), along with other active species (e.g. lanthanides), is electrochemically oxidized from the used fuel to its trivalent state $\left(\mathrm{U}^{3+}\right)$, which dissolves into a $\mathrm{LiCl}-\mathrm{KCl}$ eutectic molten salt electrolyte, nominally at $500{ }^{\circ} \mathrm{C}$. Simultaneously, $\mathrm{U}^{3+}$ in the molten salt electrolyte is preferentially reduced back to metal and collected at a solid cathode.

$$
\begin{aligned}
\text { Anode: } & \mathrm{U}(\text { anode }) \rightarrow \mathrm{U}^{3+}(\text { salt })+3 \mathrm{e}^{-} \\
\text {Cathode: } & \mathrm{U}^{3+}(\text { salt })+3 \mathrm{e}^{-} \rightarrow \mathrm{U}(\text { cathode }) \\
\text { Net: } & \mathrm{U}(\text { anode }) \rightarrow \mathrm{U}(\text { cathode })
\end{aligned}
$$

\subsection{Motivation}

The LiCl- $\mathrm{KCl}$ eutectic molten salt electrolyte has been used for uranium electrorefining due to its relatively low melting point at $628 \mathrm{~K}$ (Ref. 1), material compatibility, and chemical stability. During uranium electrorefining, the purity of the electrorefined uranium is somewhat dependent on the difference in reduction potential between the uranium and lanthanides that are dissolved from the used fuel into the electrolyte salt. The use of fluoride molten salts as electrolytes for uranium electrorefining has been studied in the past (Ref. 2 -3) with some evidence that the separation between uranium and lanthanides could be improved (Ref. 2). To further study this, work has been performed on uranium electrorefining as well as uranium and lanthanum (representing the lanthanides) behavior in the LiF-NaF-KF (FLiNaK) salt at $500{ }^{\circ} \mathrm{C}$, or the same nominal operating temperature as the chloride system, and at comparable uranium and rare earth concentrations.

\section{EXPERIMENTAL PROGRAM}

\subsection{Experimental Materials and Equipment}

All experiments were conducted in the West Development Glovebox in the Fuels and Applied Science Building (FASB) at the Materials and Fuels Complex of INL. This is an argon atmosphere radiological glovebox filled with argon in which the oxygen and moisture levels were nominally maintained below 10 ppm and $1 \mathrm{ppm}$, respectively. A well in the floor of the glovebox utilizes the Molten Salt Furnace-III (MSF-III) in which the electrochemical experiments were performed.

The molten salt electrolyte mixtures consisted of, at the base, LiF-NaF-KF (FLiNaK) eutectic salt, which has a composition of 46.5-11.5-42.0 mol\% and a melting point of $727 \mathrm{~K}$ (Ref. 4). The FLiNaK eutectic with a melting point of $727 \mathrm{~K}$ (Ref. 4) contained $46.6 \mathrm{~mol} \%$ (29.3 wt\%) LiF from AAPL (99.99+\%), 11.3 mol\% (11.5 wt \%) NaF from Sigma-Aldrich (99.99\%, anhydrous), and $42.1 \mathrm{~mol} \%$ (59.2 wt\%) KF from Alfa Aesar (99\%, anhydrous). The FLiNaK salt was initially mixed with $0.8 \mathrm{~mol} \%$ (6.0 wt $\%)$ uranium tetrafluoride $\left(\mathrm{UF}_{4}\right)$ for the first set of experiments followed by $0.55 \mathrm{~mol} \%$ ( $\left.2.4 \mathrm{wt} \%\right)$ lanthanum trifluoride from Sigma-Aldrich $\left(\mathrm{LaF}_{3}, 99.99 \%\right.$, anhydrous $)$. The pure $\mathrm{UF}_{4}$ has a very distinct bright green color as seen in Figure 1. The FLiNaK-UF 4 salt mixture was loaded into a nickel (Ni) crucible which was placed into a stainless steel secondary crucible and loaded into MSF-III. 


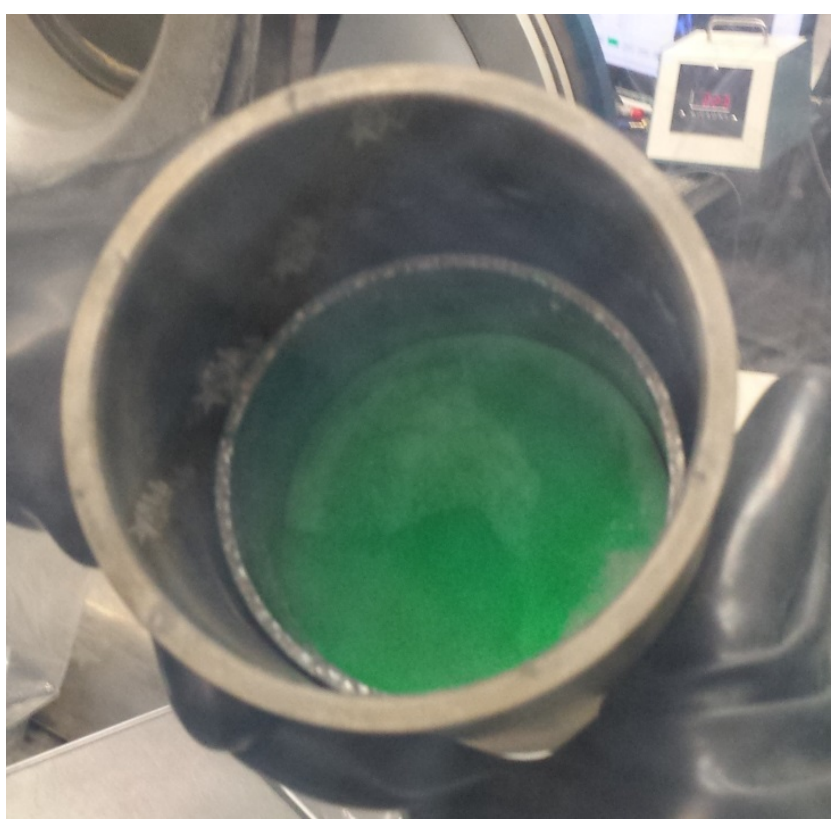

Figure 1. Uranium tetrafluoride $\left(\mathrm{UF}_{4}\right)$ salt used in electrochemical experiments.

Two types of experiments were performed, cyclic voltammetry (CV) and uranium electrorefining (ER). The CV electrochemical experiments were performed with both $\mathrm{Ni}$ and tantalum (Ta) working electrodes, an Inconel mesh basket as the counter electrode, and a glassy carbon rod (Alfa Aesar, $3 \mathrm{~mm}$ diameter) in contact with the bulk salt as a quasi-reference electrode. The uranium electrorefining experiments were conducted with a Ni rod with horizontal linear knurls as the cathode to improve uranium dendrite collection and minimize sloughing. The anode was an Inconel mesh basket filled with depleted uranium metal (DU) (Figure 2) and a glassy carbon rod was used as a quasi-reference electrode. The temperature in the salt was monitored using an Omega Inconel-sheathed Type K thermocouple.

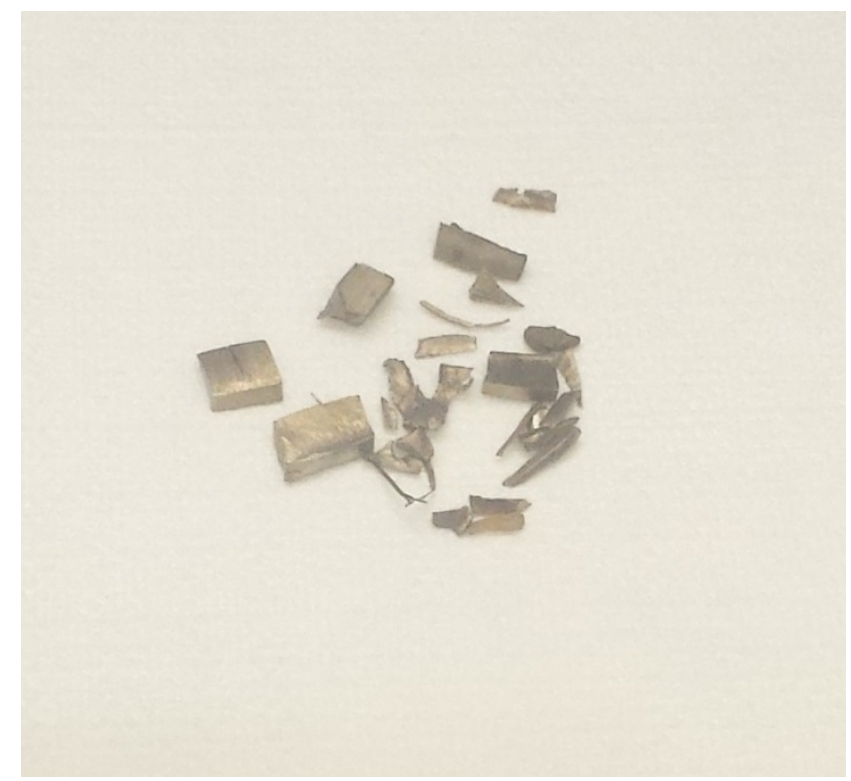

Figure 2. Depleted uranium metal used in the uranium electrorefining experiments. 


\subsection{Experimental Method}

The FLiNaK-UF 4 salt mixture in the Ni and stainless steel crucibles was loaded into the MSF-III and heated at $5 \mathrm{~K} / \mathrm{min}$ up to a temperature of $773 \mathrm{~K}$ in the salt. Once molten, a salt sample was taken using a stainless steel dip rod in order to visually examine the color of the salt mixture and returned to the bulk salt. As shown in Figure 3, the salt had a green tint to it, indicating the presence of green $\mathrm{UF}_{4}$ in the mixture.

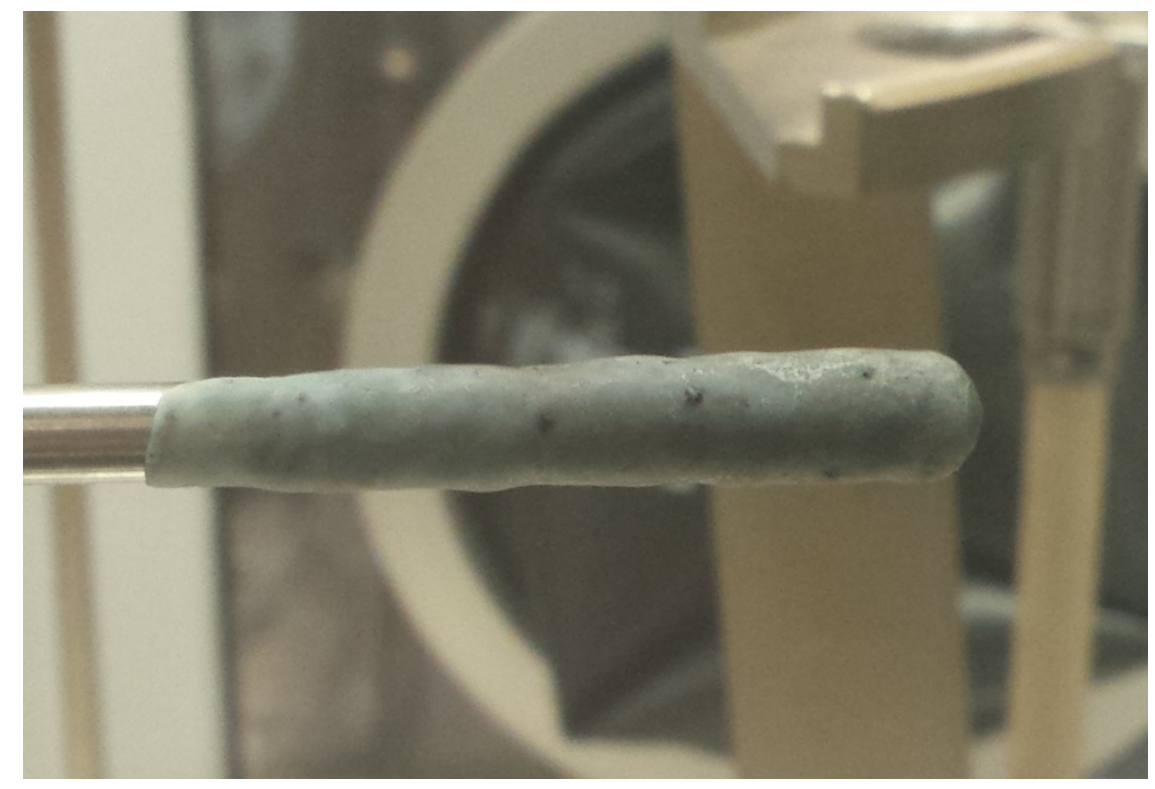

Figure 3. Sample of FLiNaK-UF 4 salt mixture.

The electrodes were lowered into the molten salt and connected to the electrode leads of a Solartron SI 1287 potentiostat as shown in Figure 4. The Solartron potentiostat along with CorrWare ${ }^{\circledR}$ electrochemical software was used to perform the cyclic voltammetry experiments. CV was conducted with a Ni working electrode in the FLiNaK- $\mathrm{UF}_{4}$ salt mixture at scan rates of 25 and $50 \mathrm{mV} / \mathrm{sec}$ and vertex potentials ranging from $-0.7 \mathrm{~V}$ to $+1.2 \mathrm{~V}$ vs. reference. 


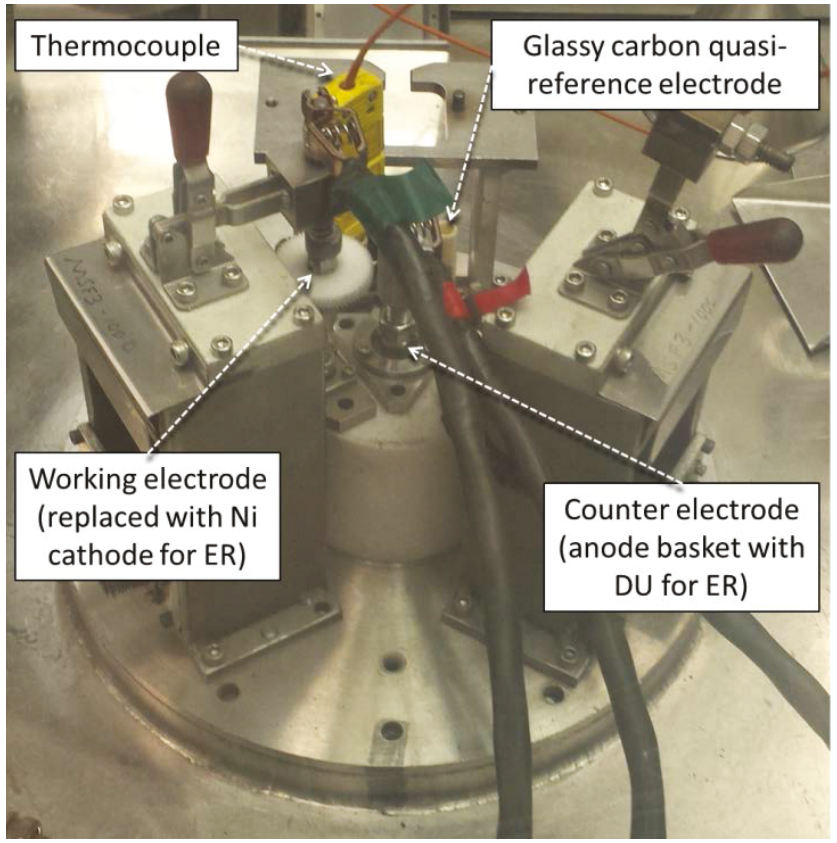

Figure 4. Experimental setup in the argon atmosphere radiological glovebox in FASB.

Following CV experiments in the FLiNaK-UF 4 salt mixture, the anode basket filled with DU was lowered into the salt bath to allow conversion of $\mathrm{UF}_{4}$ to uranium trifluoride $\left(\mathrm{UF}_{3}\right)$ via

$$
\mathrm{U}+3 \mathrm{UF}_{4} \leftrightarrow 4 \mathrm{UF}_{3} \quad \Delta \mathrm{G}_{\mathrm{r}}(773 \mathrm{~K})=-255.48 \mathrm{~kJ} / \mathrm{mol} \text { (Ref. 5) }
$$

To help facilitate this conversion, multiple uranium deposition/stripping cycles were performed. During these cycles, uranium metal was deposited onto the solid Ni cathode and then stripped back to the anode basket. In the $\mathrm{FLiNaK}-\mathrm{UF}_{4}$ salt bath during this process the following reactions occur aiding in converting the $\mathrm{UF}_{4}$ into $\mathrm{UF}_{3}$ :

$$
\begin{array}{cl}
\text { Anode: } & \mathrm{U}(\text { anode }) \rightarrow \mathrm{U}^{3+}(\text { salt })+3 \mathrm{e}^{-} \\
\text {Cathode: } & \mathrm{U}^{4+}(\text { salt })+\mathrm{e}^{-} \rightarrow \mathrm{U}^{3+}(\text { salt }) \\
& \mathrm{U}^{3+}(\text { salt })+3 \mathrm{e}^{-} \rightarrow \mathrm{U}(\text { cathode })
\end{array}
$$

Assuming full conversion, the $\mathrm{UF}_{3}$ content of the salt was $1.1 \mathrm{~mol} \%(7.4 \mathrm{wt} \%)$. As evidence of complete conversion, a uranium deposit was allowed to soak overnight in the salt bath, after which some uranium remained on the cathode rod, signifying limited to no $\mathrm{UF}_{4}$ remaining in the bath to react with the deposited uranium metal. Additionally, the salt was no longer green as seen in Figure 5. 


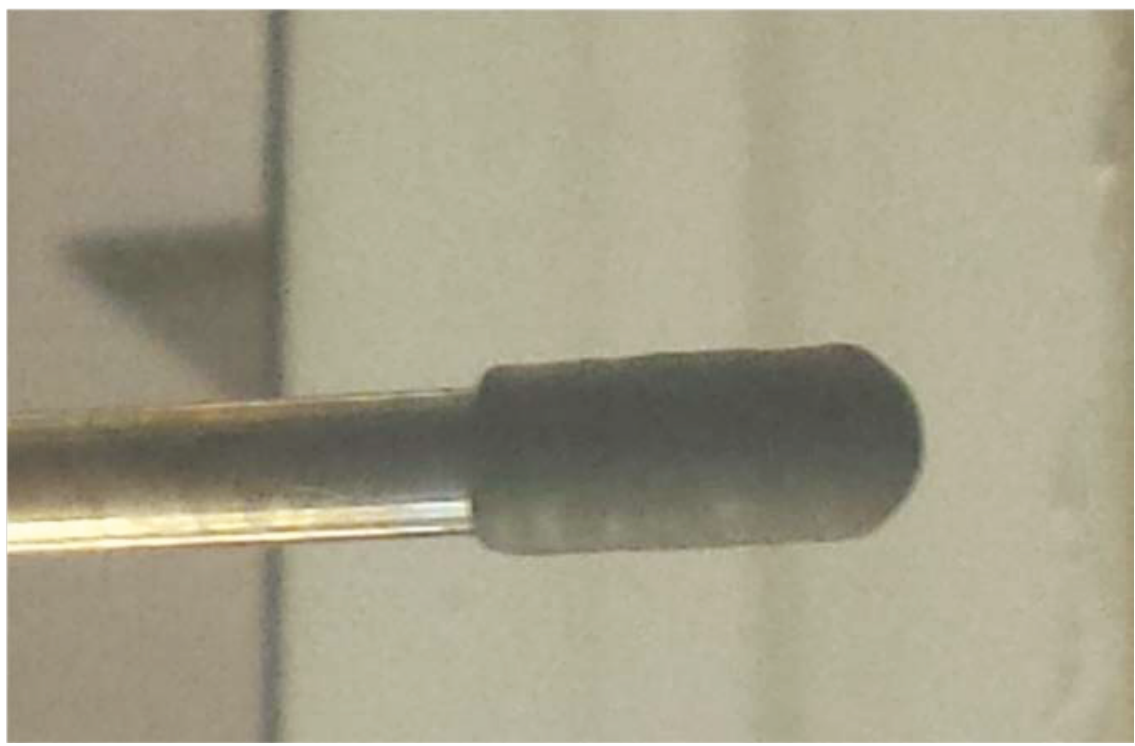

Figure 5. Sample of FLiNaK-UF 3 salt mixture.

Following the $\mathrm{UF}_{4} \rightarrow \mathrm{UF}_{3}$ conversion process, cyclic voltammetry was performed with a Ni working electrode in the FLiNaK-UF 3 salt mixture with scan rates of 25 and $50 \mathrm{mV} / \mathrm{sec}$ and vertex potentials ranging from $-0.7 \mathrm{~V}$ to $+1.6 \mathrm{~V}$ vs. reference.

After $\mathrm{CV}$ was performed on the $\mathrm{FLiNaK}-\mathrm{UF}_{3}$ salt, $\mathrm{LaF}_{3}$ was added to form a 2:1 molar U:La ratio resulting in $1.1 \mathrm{~mol} \%$ (7.2 wt $\%) \mathrm{UF}_{3}, 0.55 \mathrm{~mol} \%$ (2.4 wt\%) $\mathrm{LaF}_{3}, \mathrm{FLiNaK}_{-} \mathrm{UF}_{3}-\mathrm{LaF}_{3}$ salt mixture. Cyclic voltammetry was then performed on this salt to assess the difference in deposition potential between the uranium and lanthanum, representing the lanthanides in general. CV was operated with a Ni working electrode and scan rates of 25 and $50 \mathrm{mV} / \mathrm{sec}$ and vertex potentials from $-1.0 \mathrm{~V}$ to $+1.5 \mathrm{~V}$ vs. reference.

\section{EXPERIMENTAL RESULTS AND ANALYSIS}

\subsection{FLiNaK-UF 4 Salt Mixture}

Cyclic voltammograms in the $\mathrm{FLiNaK}_{-} \mathrm{UF}_{4}$ salt on a Ni working electrode at $773 \mathrm{~K}$ and scan rates of 25 $\mathrm{mV} / \mathrm{s}$ and varying vertex potentials are shown in Figure 6 . These scans began at the open circuit potential $(\mathrm{OCP})(+0.38 \mathrm{~V})$ and proceeded in the cathodic direction, followed by a reverse scan in the anodic direction, and ending back at open circuit. The first reduction peak, shortly cathodic of OCP at +0.26 represents the reduction of the tetravalent $\mathrm{UF}_{4}$ at the electrode surface to trivalent $\mathrm{UF}_{3}$. It should be noted that uranium can, and will, form an alloy with Ni resulting in underpotential deposition (Ref. 2-3, 6). This is likely seen in the voltammograms by an increase in negative current prior to the large reduction peak. This next, larger reduction peak, indicating the reduction of $\mathrm{UF}_{3}$ to uranium metal along with its deposition, commences at $-0.46 \mathrm{~V}$. On the return scan, the first large anodic peaks at $-0.37 \mathrm{~V}$ are due to the oxidation of uranium metal that had deposited on the working electrode back to $\mathrm{UF}_{3}$. It can be seen in Figure 6 that this peak doesn't appear until a potential more cathodic than $-0.45 \mathrm{~V}$ was reached. This supports the conclusion that reversible uranium metal deposition doesn't occur on $\mathrm{Ni}$ at potentials more positive than $-0.46 \mathrm{~V}$. The next large anodic peaks, at $+0.49 \mathrm{~V}$ is the further oxidation of soluble $\mathrm{UF}_{3}$ to soluble $\mathrm{UF}_{4}$. There exists another pair of peaks at $+0.87 \mathrm{~V}$ (anodic) and $+0.76 \mathrm{~V}$ (cathodic) having the characteristic shape of a soluble-soluble pair that likely represents the $\mathrm{U}^{5+} / \mathrm{U}^{4+}$ redox pair. The existence 
of pentavalent, as well as hexavalent, uranium in the FLiNaK molten salt has been discussed by Soucek and coworkers (Ref. 7), though the potentials at which these species exist were not reported.

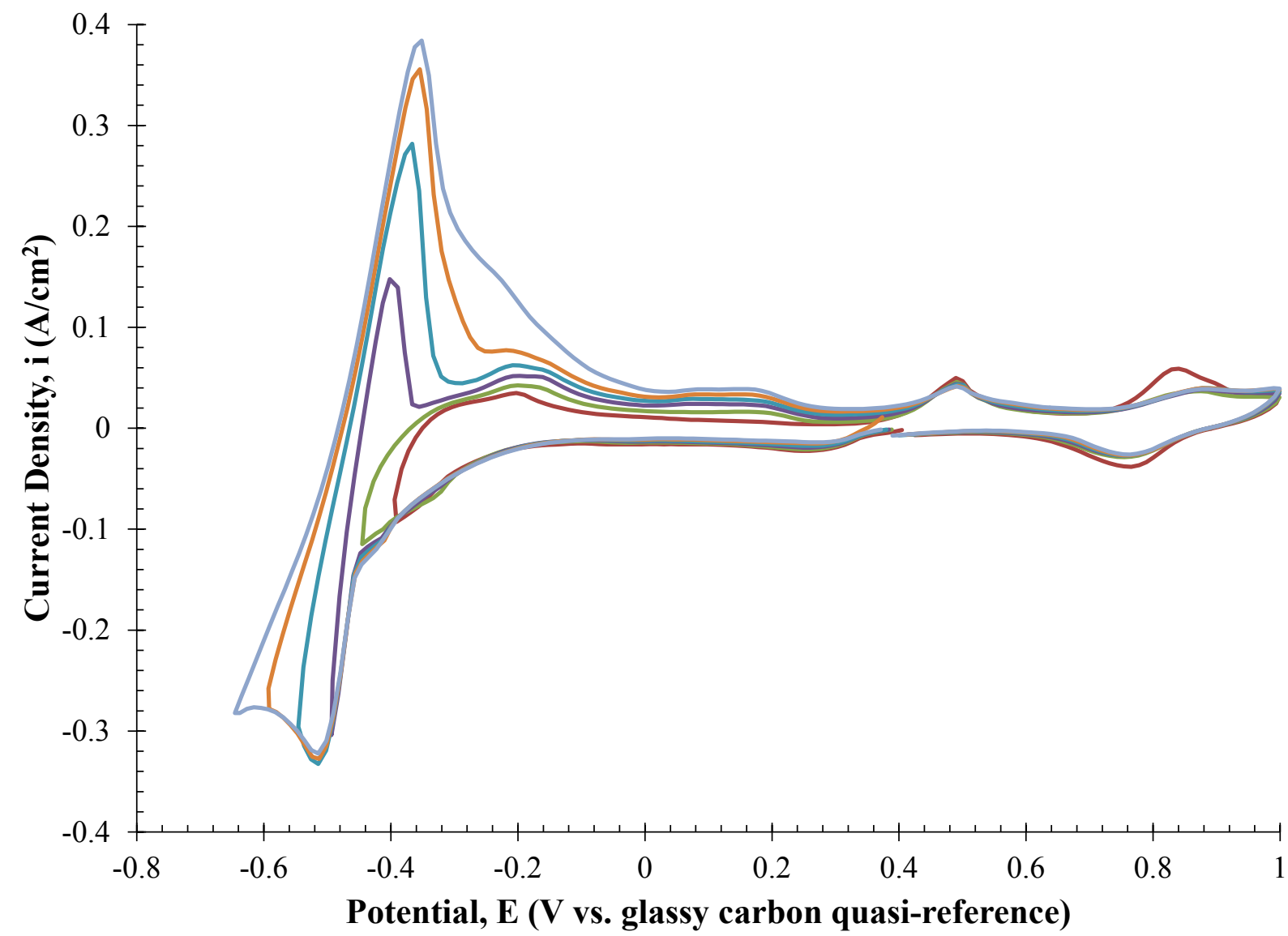

Figure 6. Cyclic voltammograms of FLiNaK-UF $4(0.8 \mathrm{~mol} \%)$ at $773 \mathrm{~K}$. Working electrode: Ni. Scan rate: $25 \mathrm{mV} / \mathrm{s}$.

\subsection{FLiNaK-UF ${ }_{3}$ Salt Mixture}

As mentioned in Section 2.2, to facilitate conversion of $\mathrm{UF}_{4}$ to $\mathrm{UF}_{3}$, multiple deposition/stripping cycles were performed using a knurled Ni rod as the cathode and a mesh Inconel basket filled with DU as the anode. Several examples of uranium electrodeposited during this conversion are shown in Figure 7. These deposits were made in controlled current mode with an applied current of $0.3 \mathrm{~A}$. On average, the resulting cathode potential was $-0.1 \mathrm{~V}$ vs the glassy carbon quasi-reference during the deposition process. It should be noted that the dendritic morphology appears very similar to uranium deposits in the $\mathrm{LiCl}-\mathrm{KCl}$ eutectic salt. 

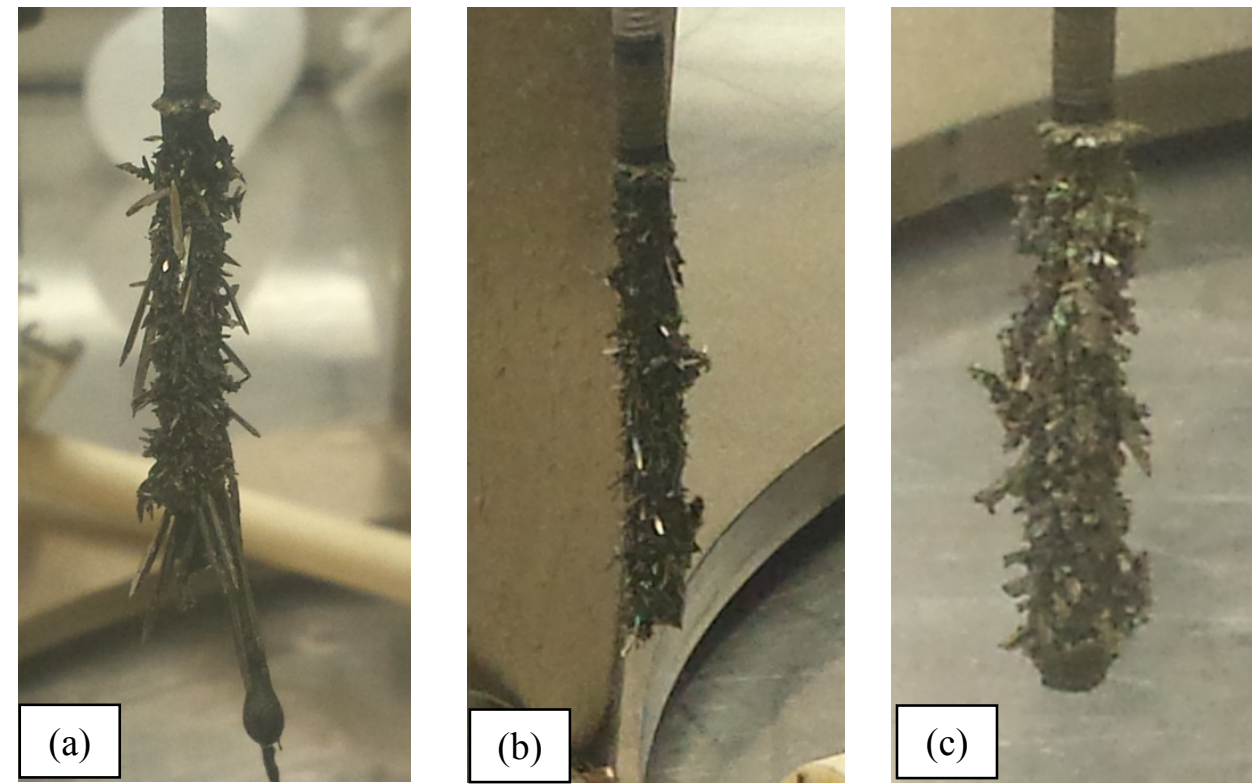

Figure 7. Examples of uranium metal electrodeposited onto a $\mathrm{Ni}$ cathode at $0.3 \mathrm{~A}$ applied current from FLiNaK-UF $-\mathrm{UF}_{3}(0.8-1.1 \mathrm{~mol} \% \mathrm{U}$ ) at $773 \mathrm{~K}$. Equivalent charge passed: (a) $3.0 \mathrm{~g} \mathrm{U}$, (b) $0.5 \mathrm{~g} \mathrm{U}$, and (c) $6.0 \mathrm{~g} \mathrm{U}$.

Following conversion of $\mathrm{UF}_{4}$ to $\mathrm{UF}_{3}$, cyclic voltammetry was performed in the FLiNaK-UF 3 salt on a Ni working electrode at $773 \mathrm{~K}$ and scan rates of $25 \mathrm{mV} / \mathrm{s}$ and varying vertex potentials with the resulting voltammograms shown in Figure 8. The first thing that is noticed is the shift in open circuit potential. In the $\mathrm{FLiNaK}_{-} \mathrm{UF}_{4}$ salt system as shown in Figure 6, the OCP was at $+0.38 \mathrm{~V}$ and just anodic of the $\mathrm{UF}_{4} / \mathrm{UF}_{3}$ reduction potential. In the FLiNaK $-\mathrm{UF}_{3}$ salt, the OCP is $+0.01 \mathrm{~V}$ and just anodic of the $\mathrm{UF}_{3} / \mathrm{U}$ potential. This shift in OCP with conversion of $\mathrm{UF}_{4}$ to $\mathrm{UF}_{3}$ was also observed by Hamel and coworkers (Ref. 3), who used a platinum wire immersed in the electrolyte as a quasi-reference electrode, and was interpreted as signifying a complete $\mathrm{UF}_{4}$ to $\mathrm{UF}_{3}$ conversion. As the scans were performed from OCP in the cathodic direction, the first peak encountered is due to uranium metal deposition, which is seen to commence at $-0.05 \mathrm{~V}$ with a peak potential at $-0.16 \mathrm{~V}$. These results are corroborated by the previously mentioned average cathode potential measured during deposition of $-0.1 \mathrm{~V}$. Upon reversal of the scan direction, the first anodic peaks at $+0.06 \mathrm{~V}$ are caused by the oxidation of the deposited uranium metal back to $\mathrm{UF}_{3}$. The next peaks of any consequence, anodic at $+1.27 \mathrm{~V}$ and cathodic at $1.19 \mathrm{~V}$ are due to the $\mathrm{UF}_{4} / \mathrm{UF}_{3}$ redox couple. 


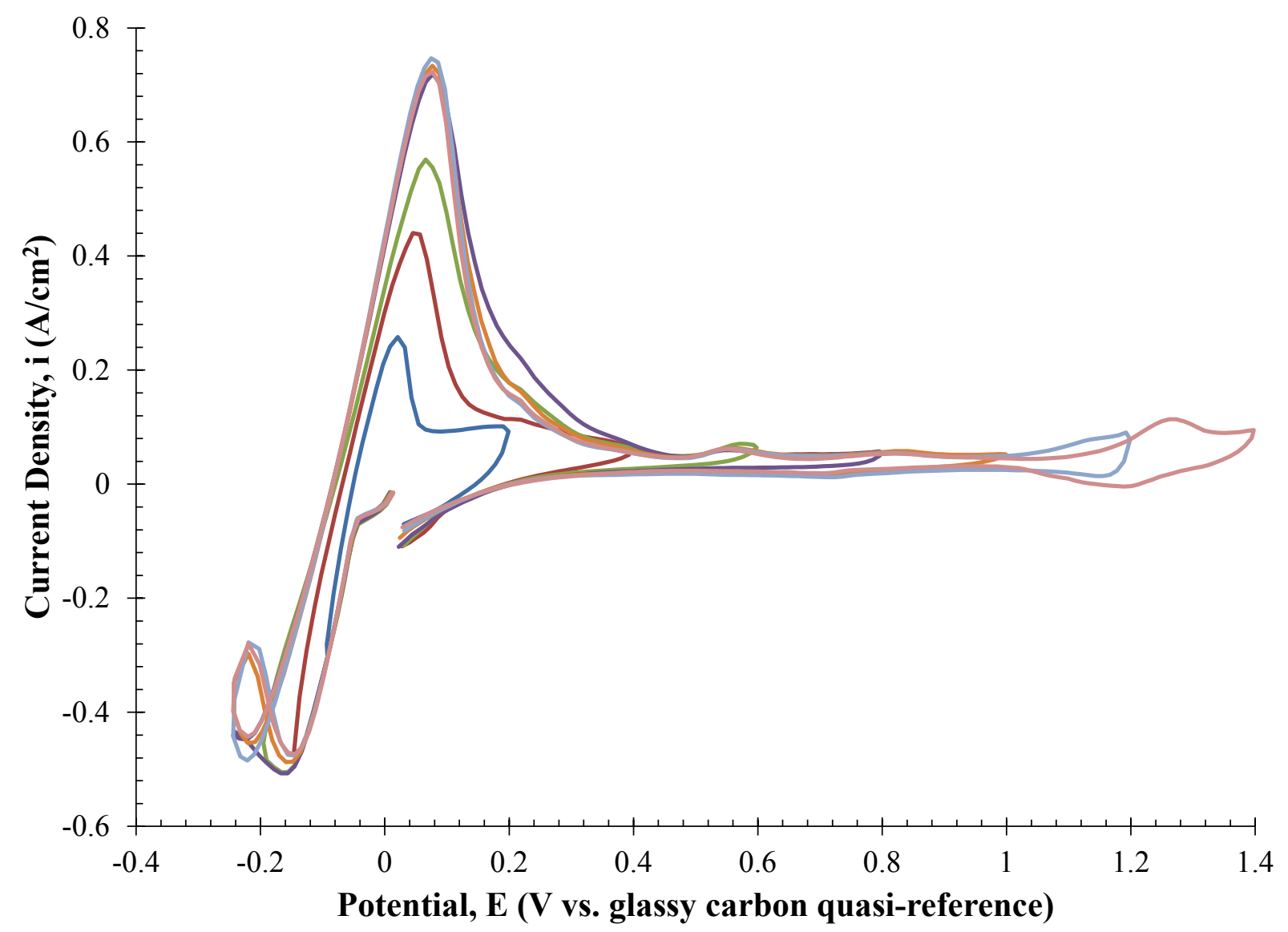

Figure 8. Cyclic voltammograms of FLiNaK-UF $3(1.1 \mathrm{~mol} \%)$ at $773 \mathrm{~K}$. Working electrode: Ni. Scan rate: $25 \mathrm{mV} / \mathrm{s}$.

\subsection{FLiNaK-UF FaF $_{3}$ Salt Mixture}

After $\mathrm{CV}$ was performed in the FLiNaK- $\mathrm{UF}_{3}$ salt mixture, $\mathrm{LaF}_{3}$ was added at $0.55 \mathrm{~mol} \%$ to achieve a $2: 1$ molar ratio of U:La in the salt. This was allowed to equilibrate overnight, with occasional stirring, to ensure a homogenous salt mixture. Cyclic voltammetry was performed in this salt with a Ni working electrode at $773 \mathrm{~K}$ and scan rates of $25 \mathrm{mV} / \mathrm{s}$ and varying vertex potentials resulting in the voltammograms shown in Figure 9. As in the previous salt mixtures, CV was started at open circuit potential, $+0.01 \mathrm{~V}$, which compares well with the CV performed in the FLiNaK-UF 3 salt. The first peak when scanning in the cathodic direction represents the reduction of $\mathrm{UF}_{3}$ and deposition of uranium metal, which begins at $-0.05 \mathrm{~V}$ and has a peak potential at $-0.15 \mathrm{~V}$. The next increase in potential is caused by $\mathrm{LaF}_{3}$ reduction and deposition of lanthanum metal, which commences at $-0.53 \mathrm{~V}$. On the return scan, the first peaks, at $-0.35 \mathrm{~V}$, are the oxidation of the deposited lanthanum to $\mathrm{LaF}_{3}$. The next, large anodic peaks occur at $+0.13 \mathrm{~V}$ and are due to the oxidation of the deposited uranium metal back to $\mathrm{UF}_{3}$. 


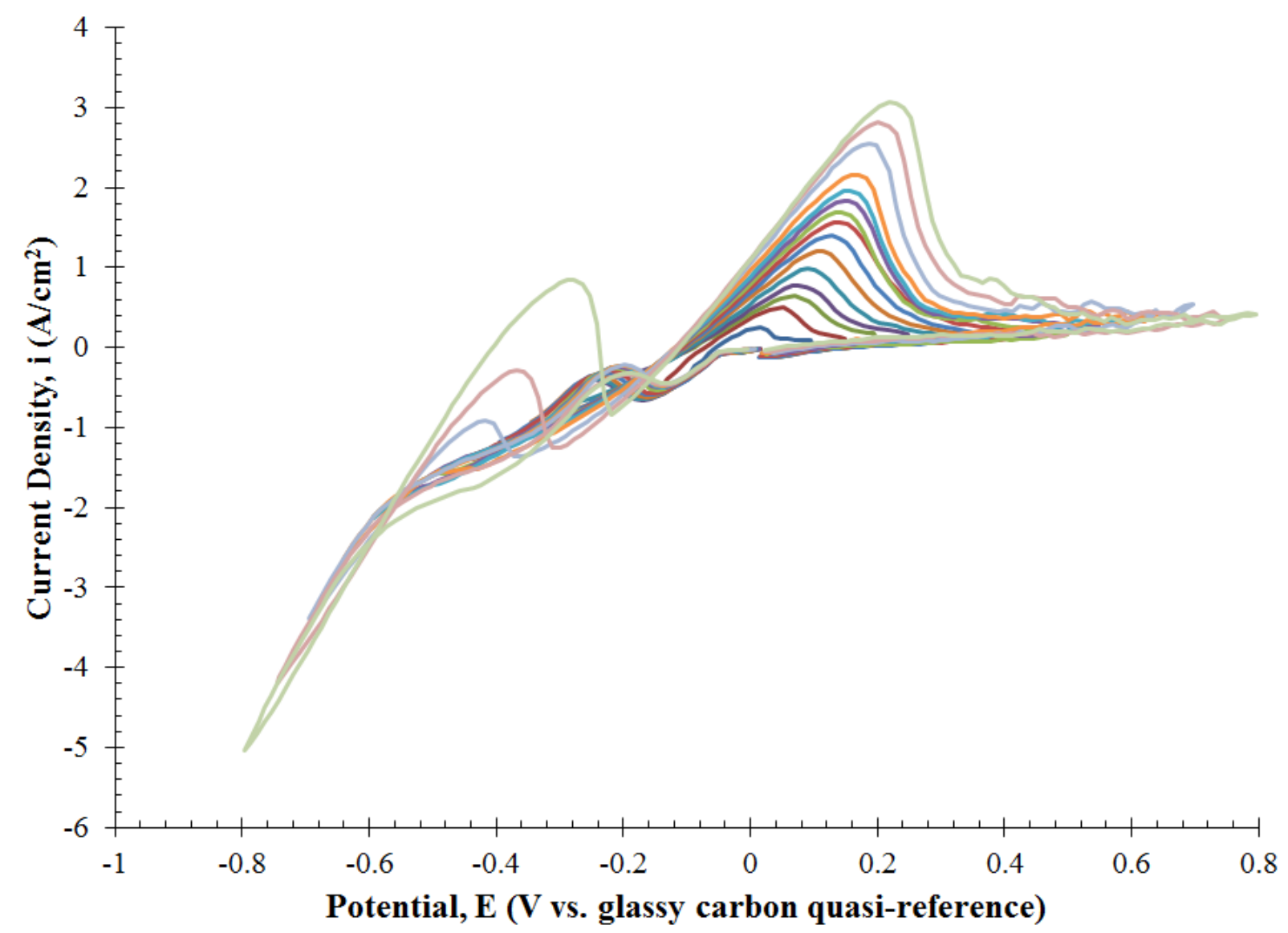

Figure 9. Cyclic voltammograms of FLiNaK- $\mathrm{UF}_{3}-\mathrm{LaF}_{3}(1.1-0.55 \mathrm{~mol} \%)$ at $773 \mathrm{~K}$. Working electrode: Ni. Scan rate: $25 \mathrm{mV} / \mathrm{s}$.

\subsection{Comparison of Salt Mixtures}

To more directly compare the results of the three different salt mixtures, representative voltammograms have been plotted together in Figure 10. As discussed previously, it is clear that there is a shift in reference potential with the change in salt composition from $\mathrm{UF}_{4}$ to $\mathrm{UF}_{3}$. Additionally, it can be seen in the figure that upon addition of $\mathrm{LaF}_{3}$ to the salt, the potential for uranium deposition does not change. In looking at the relative peak current densities, higher peak current densities for the $\mathrm{U}^{3+} / \mathrm{U}$ in the $\mathrm{UF}_{3}$ salt would be expected due to the increased concentration of $\mathrm{UF}_{3}$ that is available at the working electrode to be reduced to metal, and subsequently, oxidized back into the salt. 


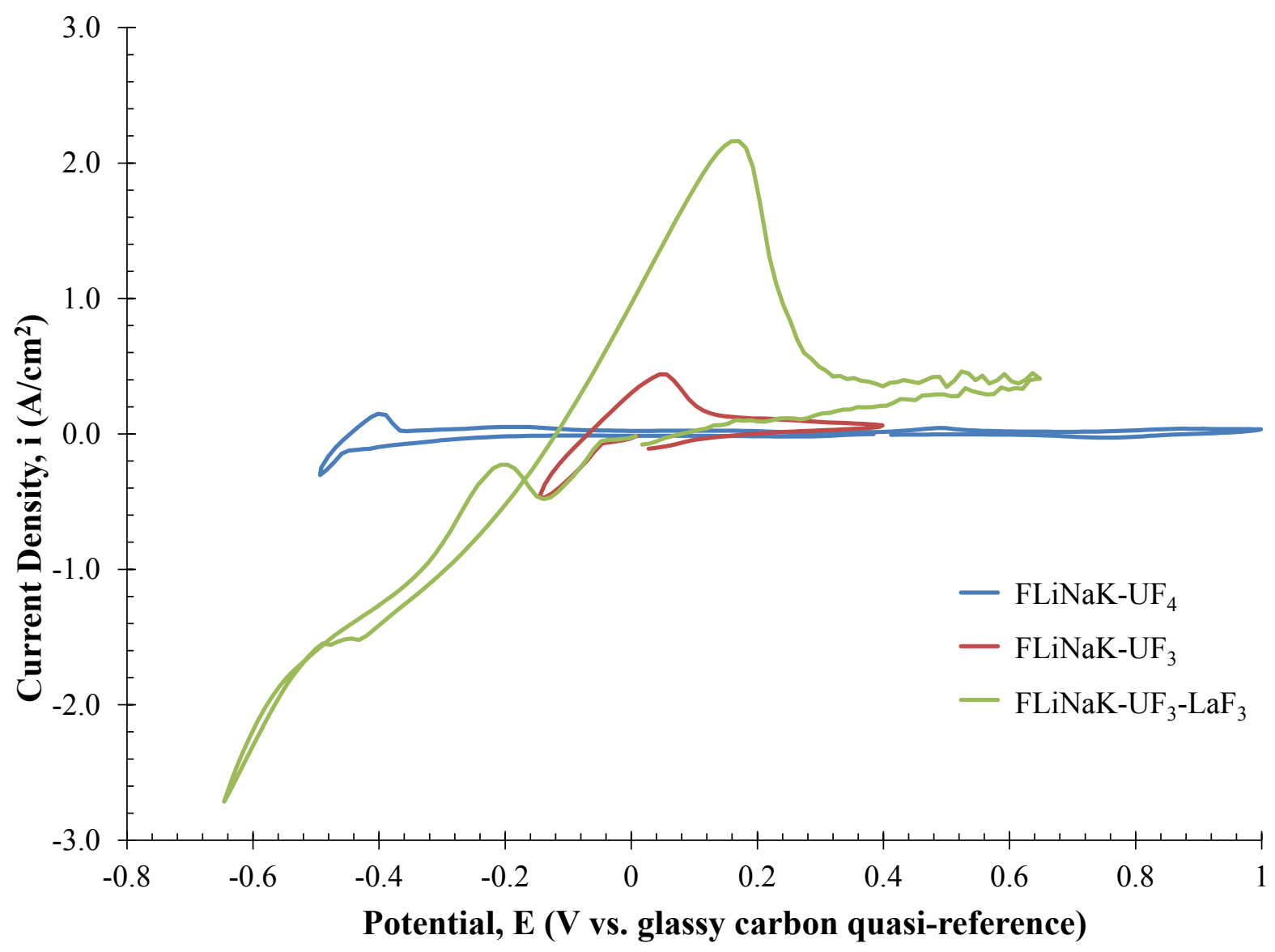

Figure 10. Comparison of cyclic voltammograms in FLiNaK-UF 4 , FLiNaK-UF 3 , and FLiNaK-UF FaF $_{3}$ at $773 \mathrm{~K}$. Working electrode: Ni. Scan rate: $25 \mathrm{mV} / \mathrm{s}$.

\section{SUMMARY AND CONCLUSIONS}

Cyclic voltammetric and electrorefining experiments have been carried out in the LiF-NaF-KF eutectic molten salt with $\mathrm{UF}_{3}, \mathrm{UF}_{4}$, and $\mathrm{LaF}_{3}$ at $773 \mathrm{~K}$. Several electrodeposited uranium cathodes were produced in the salt with dendritic morphologies similar to those seen in chloride salt uranium electrorefining at the same temperature and soluble uranium concentration. A summary of the reaction potentials as determined by analyzing the cyclic voltammograms is shown in Table 1 . These results show that, in a FLiNaK- $\mathrm{UF}_{3}-\mathrm{LaF}_{3}$ salt mixture, uranium deposition commences at $-0.05 \mathrm{~V}$ vs. a glassy carbon quasireference electrode that is in contact with the electrolyte salt. In the same salt, lanthanum deposition begins at $-0.53 \mathrm{~V}$, providing a potential window of $0.48 \mathrm{~V}$ at the cathode for collecting a lanthanum-free uranium deposit. This window is slightly smaller than that in the $\mathrm{LiCl}-\mathrm{KCl}$ system at $773 \mathrm{~K}$, which using standard reduction potentials, is reported to be $0.63 \mathrm{~V}$ (Ref. 8). 
Table 1. Summary of potentials vs glassy carbon quasi-reference electrode determined from cyclic voltammetry in the three salt mixtures.

(OCP is open circuit potential, $\mathrm{E}_{\mathrm{d}}$ is the metal deposition potential, and $\mathrm{E}_{\mathrm{pa}}$ and $\mathrm{E}_{\mathrm{pc}}$ are the anodic and cathodic peak potentials.)

\begin{tabular}{|c|c|c|c|c|c|c|c|c|c|c|c|}
\hline & \multirow{2}{*}{ OCP } & \multicolumn{3}{|c|}{$\mathrm{La}^{3+} / \mathrm{La}$} & \multicolumn{3}{|c|}{$\mathrm{U}^{3+} / \mathrm{U}$} & \multicolumn{2}{|c|}{$\mathrm{U}^{4+} / \mathrm{U}^{3+}$} & \multicolumn{2}{|c|}{$\mathrm{U}^{5+} / \mathrm{U}^{4+}$} \\
\hline & & $E_{d}$ & $\mathrm{E}_{\mathrm{pc}}$ & $\mathrm{E}_{\mathrm{pa}}$ & $\mathrm{E}_{\mathrm{d}}$ & $\mathrm{E}_{\mathrm{pc}}$ & $\mathrm{E}_{\mathrm{pa}}$ & $E_{p c}$ & $\mathrm{E}_{\mathrm{pa}}$ & $\mathrm{E}_{\mathrm{pc}}$ & $\mathrm{E}_{\mathrm{pa}}$ \\
\hline $\begin{array}{l}\mathrm{FLiNaK}^{-} \\
\mathrm{UF}_{4}\end{array}$ & +0.38 & --- & --- & --- & -0.46 & -0.51 & -0.37 & +0.26 & +0.49 & +0.76 & +0.87 \\
\hline $\begin{array}{l}\text { FLiNaK- } \\
\mathrm{UF}_{3}\end{array}$ & +0.01 & --- & --- & --- & -0.05 & -0.16 & +0.06 & +1.19 & +1.27 & --- & --- \\
\hline $\begin{array}{l}\mathrm{FLiNaK}- \\
\mathrm{UF}_{3}-\mathrm{LaF}_{3}\end{array}$ & +0.01 & -0.53 & --- & -0.35 & -0.05 & -0.15 & +0.13 & --- & --- & --- & --- \\
\hline
\end{tabular}

\section{REFERENCES}

1. J. Sangster and A.D. Pelton, "Phase Diagrams and Thermodynamic Properties of the 70 Binary Alkali Halide Systems Having Common Ions," Journal of Physical and Chemical Reference Data, 16(3), 509-561 (1987).

2. C. Hamel, P. Chamelot, P. Taxil, A. Laplace, J. Lacquement, E. Walle, "Electrochemistry of Actinides in Molten Fluoride Media: Application to the Actinides-Lanthanides Separation," Proceedings of the Atalante 2004; Nimes, France, June 21-25, 2004.

3. C. Hamel, P. Chamelot, A. Laplace, E. Walle, O. Dugne, P. Taxil, "Reduction Process of Uranium(IV) and Uranium(III) in Molten Fluorides,” Electrochimica Acta, 52, 3995-4003 (2007).

4. G.J. Janz and R.P.T. Tomkins, "Physical Properties Data Compilations Relevant to Energy Storage. IV. Molten Salts: Data on Additional Single and Multi-Component Salt Systems," U.S. Department of Commerce National Bureau of Standards report, July 1981, available at: www.nist.gov/data/nsrds/NSRDS-NBS-61-IV.pdf

5. HSC Chemistry 8, Outotec, Finland (2014).

6. D.E. Peterson, Ni-U (Nickel-Uranium), Binary Alloy Phase Diagrams, II Ed., Ed. T.B. Massalski, Vol. 3, pp. 2878-2880 (1990).

7. P. Soucek, F. Lisy, R. Tulackova, J. Uhlir, and R. Mraz, "Development of Electrochemical Separation Methods in Molten LiF-NaF-KF for the Molten Salt Reactor Fuel Cycle," Journal of Nuclear Science and Technology, 42(12), 1017-1024 (2005).

8. A.J. Bard, Encyclopedia of Electrochemistry of the Elements, Vol. X, Fused Salt Systems, p. 68, Marcel Dekker, Inc., New York (1976).

\section{ACKNOWLEDGEMENTS}

The authors would like to thank the many people at the Fuels and Applied Science Building (FASB) who made this work possible, including, but not limited to Richard Farrar, Scott Martin, Steve Steffler, and Kevin Lamont. 